\title{
Spatial Distribution of pH in the Soil Profiles of Representative Soil Series from Rice Producing Area, District Sheikhupura
}

\author{
Ghulam Nabi ${ }^{1^{*}}$, Humair Ahmed and Ijaz Ali \\ ${ }^{1}$ Land Resources Research Institute, NARC, Islamabad
}

\begin{abstract}
Soil pH is one of the chemical properties influencing the nutrient bioavailability. Most of the Pakistani soils are calcareous in nature. Keeping in view the limitations of classical statistics for explaining spatial heterogeneity a survey in the farmer grown rice fields was conducted for mapping of soil pH down the soil profile up to the depth of $100 \mathrm{~cm}$ using geo-statistics and GIS as a diagnostic tools. One hundred and seventy five soil samples were collected from the representative soil series of rice producing district Sheikhupura. Sampling was done from five depths of 012, 12-24, 24-36, 36-60 and 60-100 cm. Soil profiles were excavated and samples were collected from the five depths to examine the variation of $\mathrm{pH}$ down the soil profile. Our results indicated that soil pH at different depths was $7.80 \pm 0.45,8.09 \pm 0.42,8.29 \pm 0.50,8.39 \pm 0.54$ and $8.47 \pm 0.57$ at 0-12, 12-24, 24-36, 36-60 and 60-100 cm depth respectively. When geo-statistical analyses of the data were performed soil pH at all depths was found moderately to strongly spatial dependent (Nugget sill ratio <35). Maps were prepared to classify the whole district in to different $\mathrm{pH}$ management zones for producing regional scale information.
\end{abstract}

Keywords: GIS, geo-statistics, soil $\mathrm{pH}$, rice

\section{Introduction}

Soil $\mathrm{pH}$ is considered as a fundamental indicator for nutrient bioavailability. Predominant alkaline $\mathrm{pH}$ due to higher calcium carbonate content in the soils of Pakistan is considered as one of the restraining factor for nutrient availability to plants (Rashid et al., 1997; Ahmed et al., 2017). Acidic $\mathrm{pH}$ results in the enhanced bioavailability of nutrients like $\mathrm{B}, \mathrm{Cu}, \mathrm{Fe}, \mathrm{Mn}$ and $\mathrm{Zn}$. Bioavailability of $\mathrm{Mo}$ is higher at alkaline $\mathrm{pH}$ (Ahmed et al., 2014). Macronutrients including $\mathrm{Ca}^{+2}, \mathrm{Mg}^{+2}, \mathrm{Na}^{+}$and $\mathrm{K}^{+}$exist in higher concentration in arid soil and are not soluble in the neutral and alkaline $\mathrm{pH}$ range. Similarly bioavailability of $\mathrm{P}$ is optimum over a narrow range of $\mathrm{pH}$ i.e., 6.5 to 7.5 (Khattak, 2005; Lucas and Knezek, 1972). Therefore pH plays a vital role in the management of the nutrients for growing successful crops. One of the important distinctive characteristics of the soil variables is to show a continual spatial variability. Exploring spatial variability of soil variables serves as scientific basis for the generation of soil management strategies (Ahmed et al., 2017). Quantification of these variables from place to place and from each and every corner of the area is not possible due to laborious soil sampling analysis and usual statistical methods. However using sophisticated techniques of GIS coupled with geostatistics serve the purpose (Attar et al., 2012: Ahmed et al., 2014).

Geo-statistics has been considered as a general tool for quantification of spatial variability of soil characteristics leading to predict the values of un-sampled locations on the basis of sampled locations (Jin et al., 2012; Memon et al., 2011). Digital Mapping has been widely used to develop a numerical or statistical model of various environmental variables and soil attributes for the spatial management of soils. Spatial management of soils is associated with application system means assuming that application are made in amounts and locations where they are needed i.e. targeted application of inputs. Economically variable rate of application allows fertilizer application where response is expected and to be saved where response is unlikely (Bhatti, 2003).

Soil series represent a group of soils with similar profiles developed from similar parent materials under comparable climatic and vegetation conditions. Scientist give a lot of importance to soil series while studying soils as it provides the basis for studying soil characteristics as it includes soils similar in most of the characteristics (Razzaq and Rafique, 2005). Keeping in view the importance of the soil series as a basic unit of soil classification, GIS and geostatistics tools were used for studying spatial distribution of soil $\mathrm{pH}$ of rice producing area.

\section{Materials and Methods}

District Sheikhupura located between the $31.7167^{\circ} \mathrm{N}$ and $73.9850^{\circ} \mathrm{E}$ is one of the main rice producing area in Punjab, Pakistan and is famous for the production of quality aroma rice (Figure 1). The most extensively occurring soil

\footnotetext{
*Email: drgnabi@yahoo.co.uk
} 


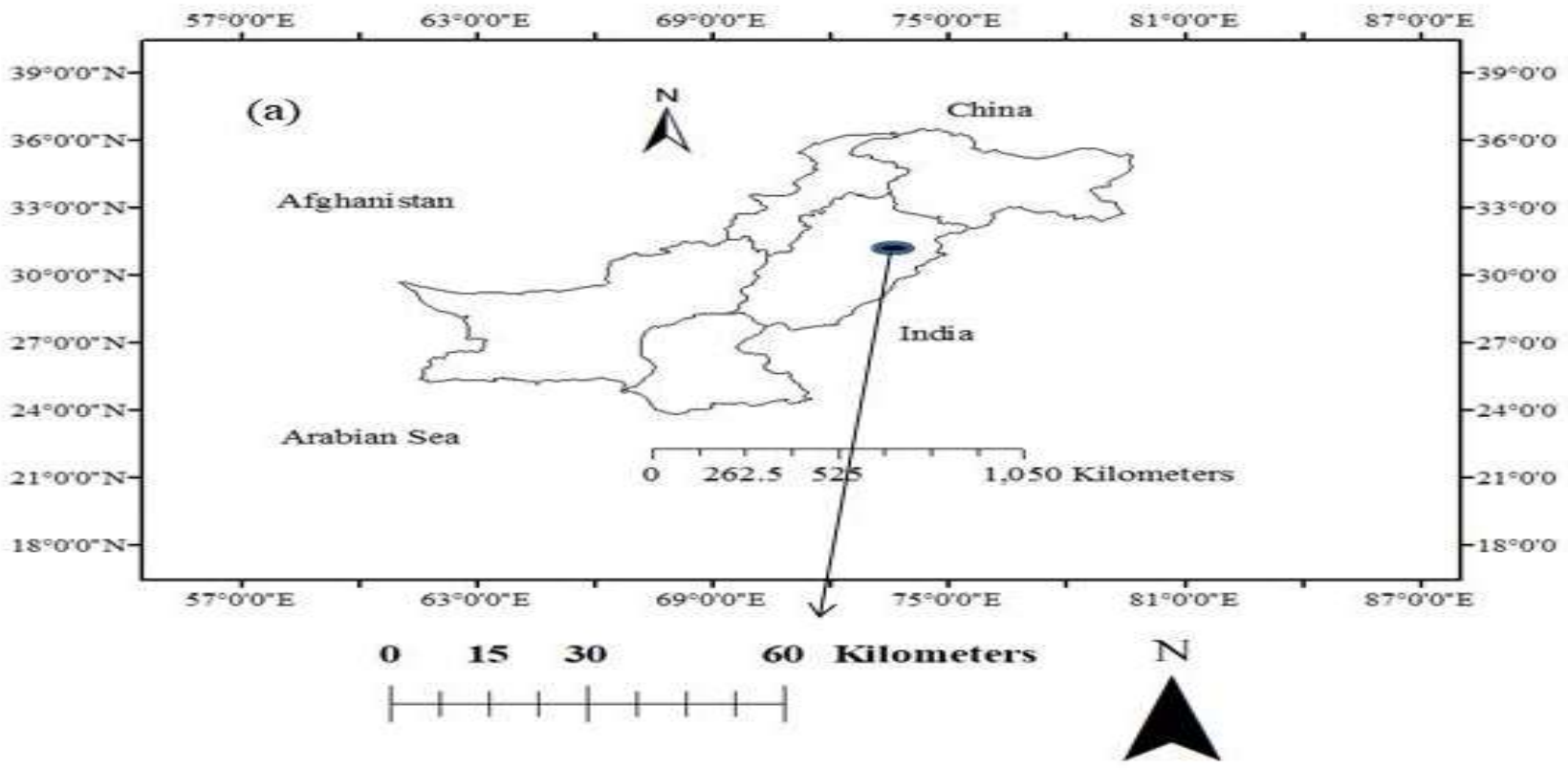

(b)

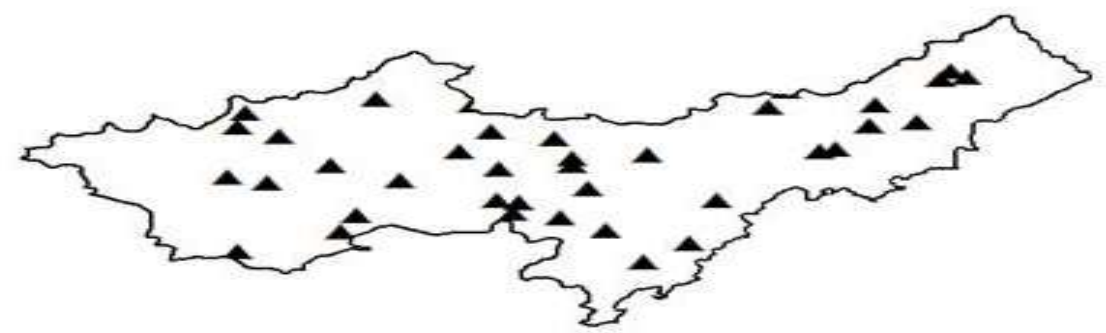

Figure 1. Geographical location of the surveyed area (a) Pakistan and sampling locations in the Sheikhupura $\operatorname{district}(\mathbf{b})$.

Table 1. Distribution of sampled sites into soil series, great group and soil orders.

\begin{tabular}{|c|c|c|c|c|c|}
\hline S. No & Series & No.of Samples & Great Group & Order & $\operatorname{Area}\left(\mathbf{k m}^{2}\right)$ \\
\hline 1 & Eminabad & 10 & Typic Natrustalfs & Alfisols & 70.0 \\
\hline 2 & Miranpur & 40 & Ustertic Camborthids & Aridisol & 1010.0 \\
\hline 3 & Bhalwal & 35 & Fluventic Camborthids & Aridisols & 381.0 \\
\hline 4 & Gujiana & 10 & Typic Natargids & Alfisols & 261.6 \\
\hline 5 & Satgarah & 30 & Typic Natargids & Aridisol & 1036.0 \\
\hline 6 & Shahpur & 25 & Fluventic Camborthids & Aridisol & 76.0 \\
\hline 7 & Miani & 10 & Fluventic Camborthids & Aridisol & 235.7 \\
\hline 8 & Shahdra & 15 & Typic Tirrifluvents & Entisols & 274.5 \\
\hline
\end{tabular}

series in the surveyed area were identified according to Soil Survey Reports (GOP, 1968). Soil sampling at each selected site was done by digging profiles of identified soil series predominating in most of Sheikhupura district having climatic conditions congenial for rice production. At each site, representative soil samples were drawn at 0 12, 12-24, 24-36, 36-60 and 60-100 cm soil depth. Sampling scheme is summarized in the Table 1. Collected 

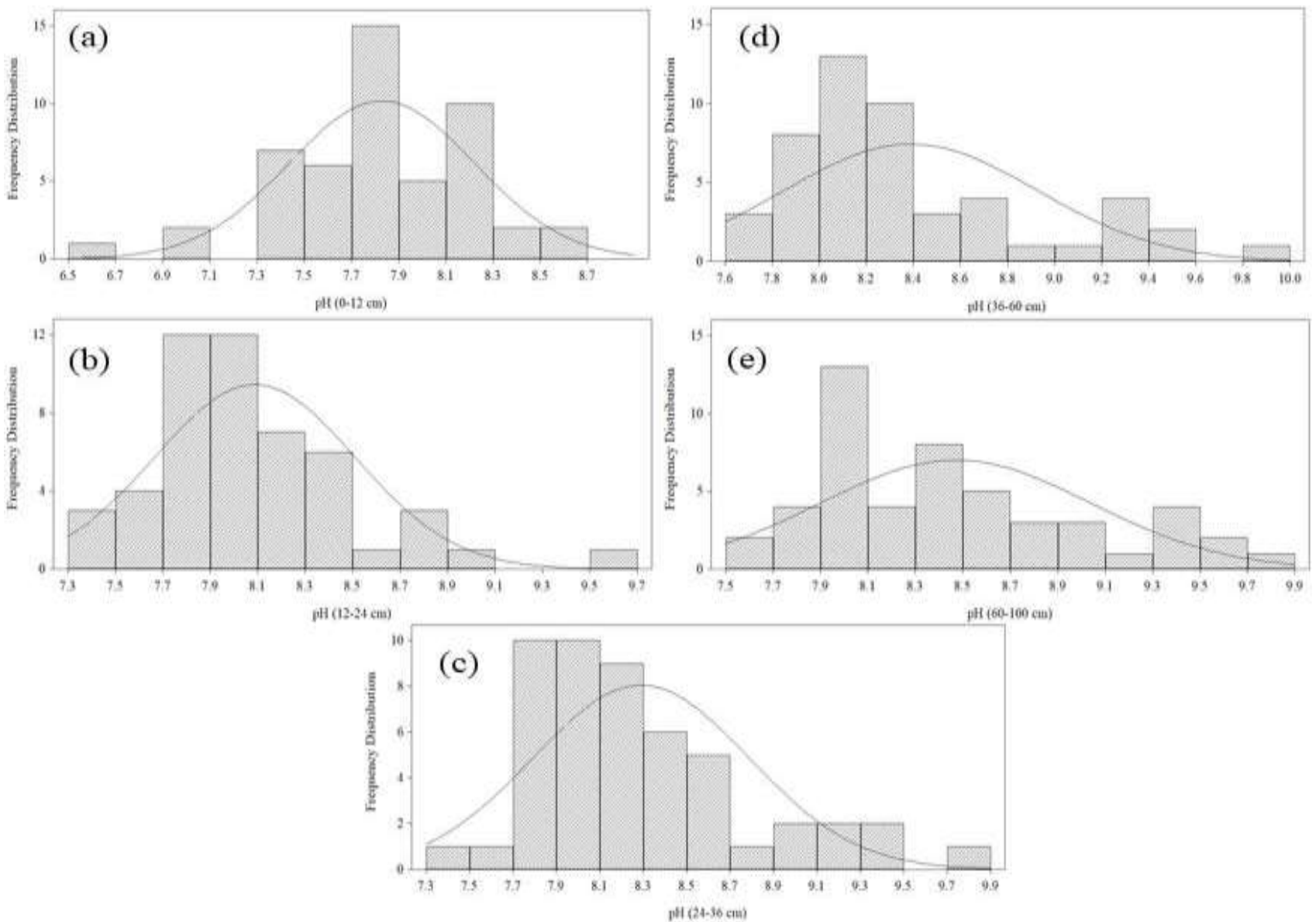

Figure 2. Frequency distribution of pH data set (a) 0-12 (b) 12-24 (c) 24-36 (d) 36-60 and (e) 60-100 cm (Bell shaped curve of frequency distribution charts indicated approximate normal distribution of data sets)

Table 2. Summary of statistical parameters used for use soil $\mathrm{pH}$ assessment in the rice area $(\mathrm{n}=175)$

\begin{tabular}{llllllll}
\hline \multirow{2}{*}{ Depth(cm) } & \multicolumn{7}{c}{ Statistical Parameters } \\
\cline { 2 - 8 } & Mean & Maximum & Minimum & SD & Skewness & Kurtosis & CV $(\%)$ \\
\hline $0-12$ & 7.80 & 8.70 & 7.30 & 0.45 & -0.96 & 1.11 & 5.76 \\
$12-24$ & 8.09 & 9.67 & 7.37 & 0.42 & 0.35 & 0.33 & 5.19 \\
$24-36$ & 8.29 & 9.83 & 7.47 & 0.50 & 0.56 & -0.11 & 6.03 \\
$36-60$ & 8.39 & 9.82 & 7.71 & 0.54 & 0.82 & -0.02 & 6.43 \\
$60-100$ & 8.47 & 9.74 & 7.65 & 0.57 & 0.78 & -1.12 & 6.72 \\
\hline
\end{tabular}

samples were sealed in air tight plastic envelope, labeled and brought to laboratory. They were air dried, ground gently and passed through a $2 \mathrm{~mm}$ sieve and were stored in plastic containers for further analysis. These samples were analyzed for $\mathrm{pH}$ according to Mclean 1982. The $\mathrm{pH}$ for each sample was determined in distilled water using soil/water ratio of 1:2(w/v). The soil/water suspensions were shaken manually every 10 minutes for 30 minutes. Values of $\mathrm{pH}$ were recorded after 1 minute of stirring. The determinations were performed at room temperature (20 \pm $2^{\circ}$ C) using Jenway $3020 \mathrm{pH}$ meter and Philips combined glass/calomel electrode (type CE1), that had previously been calibrated at $\mathrm{pH} 7.0$ and 9.0. The meter was recalibrated, when necessary to ensure accuracy. 
Data obtained was tabulated and evaluated based on descriptive statistics (mean, maximum, minimum, standard deviation of means, skewness and kurtosis). Co-efficient of variance was used to examine the variability of $\mathrm{pH}$ within the dataset. Variables having CV\% values $<15 \%$ are grouped as value of $8.09 \pm 0.42,7.47$ to 9.83 with the mean value of $8.29 \pm 0.50,7.71$ to 9.82 with the mean value of $8.39 \pm 0.54$ and 7.65 to 9.74 with the mean value $8.47 \pm 0.57$ in $0-12,12-24$, 24-36, 36-60 and 60-100 cm depth respectively. An increasing trend in the soil $\mathrm{pH}$ was observed with the increasing depth in

Table 3: Parameters related to semivariogram spherical model and interpolation of soil pH at various depths in soil profile

\begin{tabular}{rccccccc}
\hline Depth $(\mathrm{cm})$ & Range $(\mathrm{km})$ & Nugget/Sill $(\%)$ & RMSSE & RMSE & ASE & Mean Error \\
\hline $0-12$ & 0.15 & 7.20 & 1.43 & 0.45 & 0.42 & 0.010 \\
$12-24$ & 0.30 & 34.04 & 1.40 & 0.40 & 0.36 & 0.011 \\
$24-36$ & 0.14 & 27.96 & 1.70 & 0.56 & 0.53 & 0.023 \\
$36-60$ & 0.14 & 31.24 & 1.11 & 0.50 & 0.44 & 0.019 \\
$60-100$ & 0.15 & 27.05 & 1.06 & 0.52 & 0.46 & 0.012
\end{tabular}

least variable whereas those having $\mathrm{CV}$ between 15 to $35 \%$ are categorized as moderately variable. Co-efficient of variance value more than $35 \%$ indicates high variability (Wilding, 1985). Collected spatial data (coordinates) were used for geo-referencing and digitization of the base maps gained from Survey of Pakistan. Attribute data were used for geostatistical analyses (kriging). Generation of digital maps was accomplished by simulation of geo-statistically analyzed data within the boundaries of digitized maps. The validation and the fitness of the interpolation method were tested via cross validation (Leuangthong et al., 2004). Cross validation estimation is obtained by leaving one sample out and using the remaining data to estimate the value (Ahmed et al., 2017). This test allows evaluating the goodness of fit of the method and the appropriateness of neighborhood, while the interpolation values are compared to the real. The efficacy of applied techniques was evaluated using mean error calculated by the formula (Equation 1) and RMSE calculated by the formula (Equation 2).

$$
\begin{array}{ll}
M E=\frac{1}{n} \sum_{i=0}^{n}\left[Z^{*} x_{i}-Z x_{i}\right] & \text { Equation 1 } \\
\text { RMSE }=\left[\sum_{i=0}^{n}\left(Z^{*} x_{i}-Z x_{i}\right)^{2} / N\right]^{\frac{1}{2}} & \text { Equation 2 }
\end{array}
$$

Where $Z^{*}\left(x_{i}\right)$ and $Z\left(x_{i}\right)$ reperesents the observe and predicted values respectively.

\section{Results and Discussion}

\section{Descriptive statistical analysis}

Data regarding soil $\mathrm{pH}$ of analyzed samples collected at five depths in different soil series is summarized in the Table 1. Our results indicated that soil $\mathrm{pH}$ ranged from 7.30 to 8.70 with the mean value of $7.80 \pm 0.45,7.37$ to 9.67 with the mean the soil profile of all the sampled soil series which might be due to leaching of salts like $\mathrm{CaCO}_{3}$ down the soil profile in rice producing area as the crop is grown in the flooded water conditions. Calcium carbonate content in the soils ranged from 1.5 to 15.9 percent with the mean value of $8.5 \pm 1.5$. An increase trend in $\mathrm{CaCO}_{3}$ content was also observed with increasing depth. Leaching of $\mathrm{CaCO}_{3}$ is a soil forming processes for all calcareous soils in areas where precipitation exceeds evapotranspiration losses of water, however calcium carbonate is not removed from the soil profile but it is redistributed in the soil profile (Arkley, 1963). Soil $\mathrm{pH}$ of all the studied profiles was found favorable for growing crops having fibrous root system instead of deep rooted crops. Data set indicated the soil $\mathrm{pH}$ was found least variable at all soil depths as CV\% value was found to be less than $15 \%$. Skewness, kurtosis (Table 2) and frequency distribution plot (Figure 2) indicated that data set were approximately normally distributed.

\section{Geostatistical analysis and mapping of $\mathrm{pH}$ in the studied soil profiles}

Semivariogram modelling was done to examine the spatial dependence of soil $\mathrm{pH}$ at various soil depths (Figure 3). Parameters related to semivariogram modelling and cross validation are summarized in Table 3. Spatial structure of the soil $\mathrm{pH}$ at all the sampled depths from $0-100 \mathrm{~cm}$ was best explained by spherical model which is modified quadratic function, (Robertson, 2008) (Figure 4). The equations used for spherical modelling are as under:-

$$
\begin{aligned}
& \gamma(\mathrm{h})=\mathrm{C} 0+\mathrm{C}[1.5(\mathrm{~h} / \mathrm{A} 0)-0.5(\mathrm{~h} / \mathrm{A} 0) 3] \text { for } \mathrm{h} \leq \mathrm{A} 0 \\
& \gamma(\mathrm{h})=\mathrm{C} 0+\mathrm{C} \text { for } \mathrm{h}>\mathrm{A} 0
\end{aligned}
$$


Where $\gamma(\mathrm{h})=$ semivariance for interval distance class $\mathrm{h}, \mathrm{h}=$ the lag distance interval, $\mathrm{C} 0=$ nugget variance $\geq 0, \mathrm{C}=$ structural variance $\geq \mathrm{C} 0$, and $\mathrm{A} 0=$ range parameter. In the case of the spherical model, the effective range $\mathrm{A}=\mathrm{A} 0$. Our results
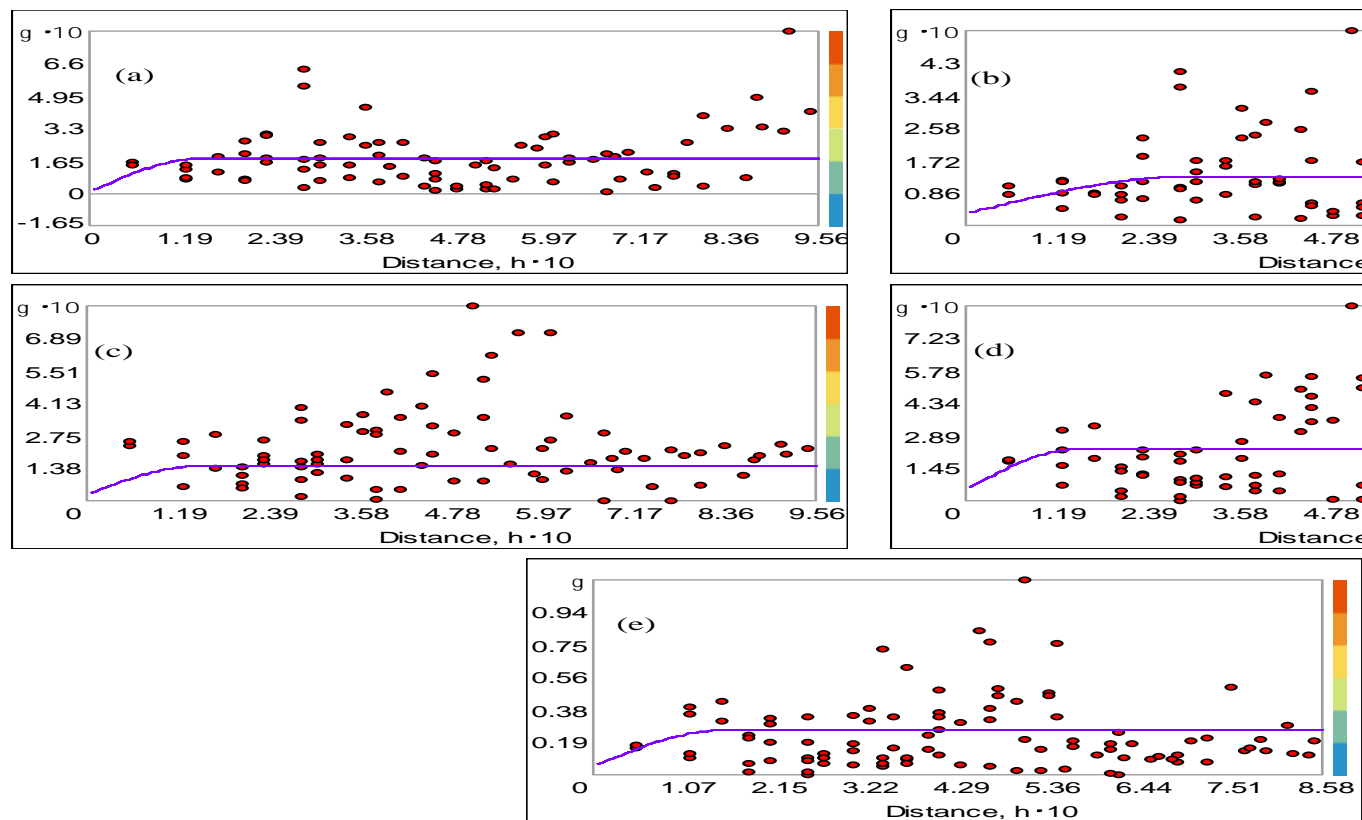

Figure 3. Semivariograms of pH data set (a) 0-12 (b) 12-24 (c) 24-36 (d) 36-60 (e) $60-100 \mathrm{~cm}$
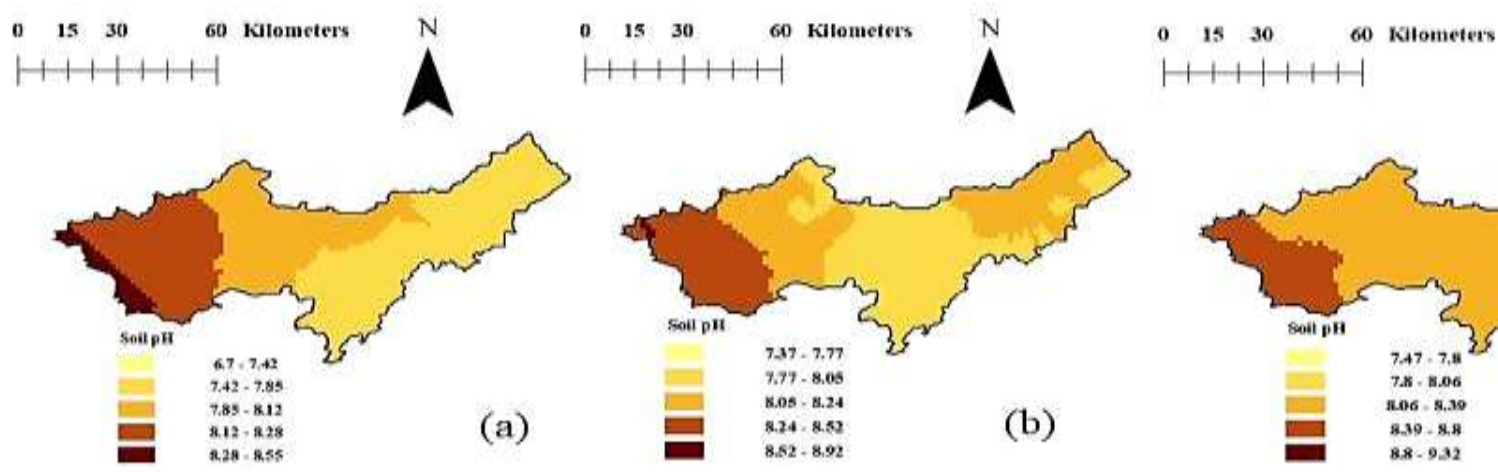

i
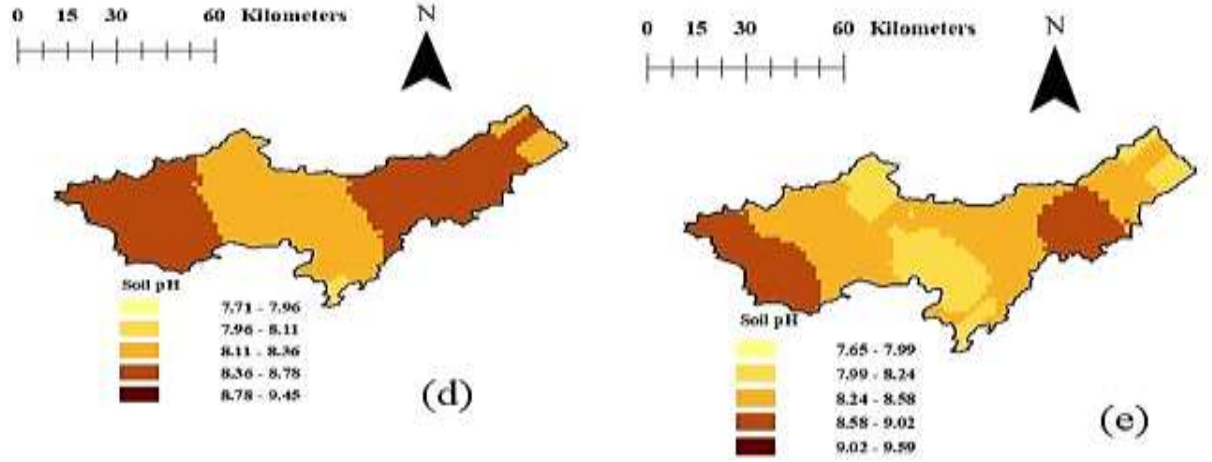

Figure 4. Spatial distribution of soil pH in the soil profile (a) 0-12 (b) 12-24 (c) 24-36 (d) $36-60$ (e) $60-100 \mathrm{~cm}$ 
preparing digital maps otherwise specific protocols are needed to be followed for maps generation. Therefore, moderate to strong spatial dependence provided us an opportunity to prepare digitals maps for estimating soil $\mathrm{pH}$ vertically up to the depth of $100 \mathrm{~cm}$ in a soil profile. Spatial dependence of soil $\mathrm{pH}$ was found to be maintained by anthropogenic activities like cultivation, addition of chemical fertilizers and organic manure at surface soils while in the lower soil depths intrinsic soil factors governing soil $\mathrm{pH}$ like parent materials might be responsible for the maintaining moderate to strong spatial dependence in the soils (Liu et al., 2004; Spiker et al., 2005; Chunfa et al., 2010; Banerjee et al., 2011).

Moreover, RMSE and ASE (Table 3) values indicated the authenticity of prepared digital maps at all soil depths up to $100 \mathrm{~cm}$ (Ahmed et al., 2014). Prepared maps indicated a great variation of soil $\mathrm{pH}$ in the studied area and $\mathrm{pH}$ varied from neutral to slightly alkaline and strongly alkaline in the whole soil profile. Prepared maps also indicated an increase of $\mathrm{pH}$ with the increasing depth in the soil profile. Prepared maps indicated that soil $\mathrm{pH}$ was neutral to slightly alkaline in the north eastern areas of surveyed region. Non calcareous sandy clay loam or clay loams occur in the basins and channel fills of river terraces might be responsible for this soil pH (GOP, 1968). These soils are deeply developed and humified. There natural fertility is relatively high and are subject to flooding by runoff water from the adjoining higher land. Therefore, they are mainly used for rice production. Slightly acidic $\mathrm{pH}$ predicted in the soils might be due to existence of Miranpur soil series covering about $1010 \mathrm{~km}^{2}$, which is well drained and has moderately developed soil structure. Presence of canker zone down the soil profile is one of the major causes for alkaline $\mathrm{pH}$ in the soil profile. Other soil series sampled during the survey were found to be alkaline in nature due to presence of calcium carbonate. Soil series Satgrah and Eminabad are saline, alkali and $\mathrm{pH}$ generally above 9, with the dense sub soils (GOP, 1968).

\section{Conclusion}

Surface soils of the surveyed area were found neutral to alkaline in nature having $\mathrm{pH}$ value of 6.80 to 7.77 in the upper surface soils $(0-24 \mathrm{~cm})$. Semivariogram modeling indicated a strong spatial dependence on the surface soils while moderate spatial dependence in the lower soil depths was observed. Digital maps indicated that the surface soils up to the depth of $0-24 \mathrm{~cm}$ were found favorable for growing crops having fibrous root system.

\section{Acknowledgement}

Authors are highly obliged to Pakistan Agricultural Research Council for financial support during study period under RADP project.

\section{References}

Ahmed, H., M. T. Siddique, M. Iqbal and F. Hussain. 2017. Comparative study of interpolation methods for mapping soil $\mathrm{pH}$ in the apple orchards of Murree, Pakistan. Soil and Environment. 36(1): 70-76.

Ahmed, H., M. T. Siddique, S. Ali, N. A. Abbasi, A. Khalid and R. Khalid. 2014. Micronutrient indexing in the apple orchards of Northern Punjab, Pakistan using geostatistics and GIS as diagnostic tools. Soil and Environment 33: 07-16.

Arkley, R.J. 1963. Calculation of carbonate and water movements in soils from climatic data. Soil Science. 96: 239-248.

Attar, A., A. Jafarnejadi, G. Sayyad and A. Gholami. 2012. Spatial variability of iron and zinc concentrations in the soils of wheat farms. Advances in Environmental Biology 6: 1620-1625.

Banerjee, S., A. B. Haughn, B. C. Si and S. D. Siciliano. 2011. Soil spatial dependence in three arctic ecosystems. Soil Biol. Biochem. 75: 591 - 594.

Bhatti, A.U. 2003. Spatial variability and its management in agriculture. Higher Education Commission of Pakistan. p. 86-91.

Chunfa, W. U., L. Yongming and Z. Limin. 2010. Variability of copper availability in paddy fields in relation to selected soil properties in south east china. Geoderma, 156: 200 - 206.

GOP. 1968. Reconnaissance soil survey; "Sheikhupura Area". Soil Survey of Pakistan, Lahore.

Jin, J.W., H.C. Ye, Y.F. Xu, C.Y. Shen and Y.F. Huang. 2012. Spatial and temporal pattern of soil fertility, quality and analysis of related factors in urban-rural transition zone of Beijing. Advances in Environmental Biology 6: 1620-1625.

Khattak, R. A. Chemical properties of soils. 2005. p. 167205. In: Soil Science. Bashir. E and R. Bantel, (eds). National Book Foundation Islamabad.

Leuangthong O., J.A. McLennan and C.V. Deutsch. 2004. Minimum acceptance criteria for geostatistical realizations. Natural Resources Research 13:131-141.

Liu, X. M., J. M. Xu, M. K. Zhang, J. H. Huang, J. C. Shi and X. F. Yu. 2004.Application of geostatistics and GIS technique to characterize spatial variabilities of bioavailable micronutrients in paddy soils. Environmental Geology., 46: 189 - 194.

Lucas, E. and Knezek. Climate and soil conditions promoting micronutrient deficiencies in plants.1972. p. 265-287. In: Micronutrients in agriculture. Mortvedt, J. J., P. M. Giordano and W. L. Lindsay, (eds). Soil Science Society of America, Inc. Madison, Wisconsin USA. 
Mclean, E.O. 1982. Soil pH and lime requirement. p. 198209. In: Methods of Soil Analysis, Part 2: Chemical and Microbiological Properties. A.L. Page, R.H. Miller and D.R. Keeney (eds.). American Society of Agronomy. Madison, WI, USA.

Memon, A.R., S. Khalid, A. Mallah and A.A. Mirbahar. 2011. Use of GPS and GIS technology in surveying and mapping of wheat and cotton weeds in Khairpur district, Sindh, Pakistan. Pakistan Journal of Botany 43: $1873-1878$.

Rashid, A., E. Rafique, N. Bughio and M. Yasin. 1997. Micronutrient deficiencies in rainfed calcareous soils of Pakistan. IV. Zinc nutrition of sorghum. Communications in Soil Science and Plant Analysis 28: 455-467
Razzaq, A and M. Rafique. Soil classification and survey. 2005. p. 405-438. In: Soil Science. Bashir. E and R. Bantel, (eds). National Book Foundation Islamabad.

Robertson, G.P. 2008. GS ${ }^{+}$: Geostatistics for the Environmental Sciences. Gamma Design Software, Plainwell, Michigan USA.

Spiker, J., S. P. Vriend, and P. F. M. Vans-Ganns. 2005. Natural and anthropogenic patterns of covariance and spatial variability of minor and trace elements in agricultural top soil. Geoderma, 127: $24-35$.

Wilding, L.P. 1985. Spatial variability: It's documentation, accommodation and implication to soil surveys. pp. 166-194. In: Soil Spatial Variability. D.R. Nielsen and J. Bouma (eds.). Pudoc, Wageningen, Netherland 